\title{
In vitro effect of tuibur (tobacco brew) on the viability of human blood lymphocytes
}

\author{
B. Lalruatfela*, Jennifer Zoremsiami and Ganesh Chandra Jagetia \\ Department of Zoology, Mizoram University, Aizawl 796004, Mizoram, India
}

\begin{abstract}
The use of tobacco and its products are known to cause many illnesses including cancer. A smokeless tobacco locally manufactured called tuibur (tobacco brew) has been consumed by the Mizos from a very long time. In this experiment we aim to determine the cytotoxicity of tuibur by an in vitro study on tuibur-treated human peripheral blood lymphocytes. We have found that $24 \mathrm{~h}$ treatment of human lymphocytes with two grades of commercial tuibur and nicotine showed a concentration dependent decrease in cell viability. We, therefore, concluded that as the in vitro use of tuibur has an adverse effect on cell survival, its consumption might have potential side effects on the health of the users.
\end{abstract}

Key words: Cell viability, lymphocytes, tobacco, tuibur.
Received 17 February 2017 Accepted 20 March 2017

*For correspondence $\triangle$ b.atetea@gmail.com

\section{Introduction}

Tobacco is linked with many diseases and has been known to contain more than eight thousand chemicals, out of which roughly 68 are probable carcinogens. ${ }^{1-3}$ Some of the common toxic chemicals include benzo[a]pyrene $(B[a] P)$, $\mathrm{N}^{\prime}$-nitrosonornicotine $(\mathrm{NNN}), \quad \mathrm{N}^{\prime}$ nitrosoanatabine (NAT), $\quad \mathrm{N}^{\prime}$-nitrosoanabasine (NAB), 4-(methylnitrosamino)-1-(3-pyridyl)-1butanone (NNK), N-nitrosodimethylamine (NDMA), nitrite, cadmium, lead, arsenic, nickel, chromium, etc. ${ }^{4,5}$ The consumption of both smoking and smokeless tobacco is popular throughout the world and its detrimental effect could be observed from many medical records.
Besides its deleterious consequence upon the pulmonary system, it has been linked with many forms of cancer. In fact, many studies suggested that almost all known cancer could be linked to tobacco use. ${ }^{6,7}$

It would be safe to say that every nation throughout the globe has tobacco users in its population. ${ }^{8}$ The form of tobacco used may vary considerably. Some prefer smoking tobacco while others prefer smokeless tobacco, or both. But, it may be acceptable to say that more than half of the tobacco users used it in the form of smoking tobacco. ${ }^{9}$ The Mizo tribes living in the northeastern part of India use both smoke and smokeless tobacco. ${ }^{10}$ A form of smokeless tobacco locally called tuibur (tobacco brew) is used popularly and is commercially available in the 
local market, generally in two grades, which largely depend on the amount of tobacco used in its production. The method of practice is the users of tuibur put the product in the mouth for roughly 5-10 minutes which is then spitted out. The duration is determined when the alkalinity of the tuibur is depleted. ${ }^{11}$

In this experiment, we aimed to determine the effect of two grades of commercial tuibur on the viability of tuibur-treated human peripheral blood lymphocytes in vitro.

\section{Materials and Methods}

\section{Chemicals}

A small quantity of two grades of commercial tuibur, labelled as tuibur-A (special grade) and tuibur-B (ordinary grade), produced in a local industry were purchased from the market. Although there is no standard protocol, the manufacturers graded the tuibur depending on the quantity of tobacco used in its production. Pure nicotine (Cayman Chemical Company) and trypan blue (Sigma) were purchased from local supplier. RPMI-1640 media (HiMedia) was obtained from local supplier and prepared in the laboratory using standard protocol.

\section{Lymphocyte culture and treatment}

Lymphocyte culture were performed using the protocol described by Jagetia et al. ${ }^{12}$ Briefly, peripheral blood lymphocytes were collected by venipuncture in a heparinized vacutainer from a 27-year-old healthy male volunteer who has no known history of tobacco consumption. The collected blood was allowed to stand for roughly half an hour and the upper translucent layer containing lymphocytes was taken for culture. Approximately two million lymphocytes were cultured in different test tubes containing $2 \mathrm{ml}$ RPMI- 1640 culture media without the addition of any growth factor.

The tubes were separated into four groups ( $I$, II, III \& IV) and different volumes of tuibur-A and tuibur-B were added to group I \& II $(2.5,5,10$, 20,40 , and $50 \mu \mathrm{l} / \mathrm{ml}$ ) respectively. To group III, $2.5,10,20,40$, and $50 \mu \mathrm{g} / \mathrm{ml}$ of nicotine was added and this served as positive control. Group IV or blank acted as negative control and did not contain any chemical other than the cells and the media. All cultures were performed in triplicate. These tubes were incubated at $37^{\circ} \mathrm{C}$ for $24 \mathrm{~h}$. After $24 \mathrm{~h}$, the survival of the cells was checked by modified trypan blue exclusion assay. ${ }^{13}$ The number of living and dead cells were counted in a hemocytometer and the mean percentage of surviving cells was taken as viability.

\section{Statistical analysis}

All statistical analysis were performed using Microsoft Excel 2013 and OriginPro-8. Correla-

Table 1 | Mean percentage of viable human peripheral blood lymphocytes for blank and treatment with different concentration of tuibur- $A$, tuibur- $B$ and nicotine.

\begin{tabular}{ccccc}
\hline \multirow{2}{*}{$\begin{array}{c}\text { Concentration } \\
(\mu \mathrm{l} / \mathrm{ml} \text { or } \mu \mathrm{g} / \mathrm{ml})\end{array}$} & \multicolumn{4}{c}{ Mean \% of viable cells \pm SEM } \\
\cline { 2 - 5 } & Tuibur-A & Tuibur-B & Nicotine & Blank \\
2.5 & - & - & - & $100.00 \pm 0.00$ \\
\hline 5 & $100.00 \pm 0.00$ & $100.00 \pm 0.00$ & $98.25 \pm 0.06$ & - \\
10 & $96.39 \pm 0.58$ & $95.06 \pm 0.40$ & $96.55 \pm 0.25$ & - \\
20 & $90.34 \pm 1.86$ & $90.35 \pm 0.97$ & $92.32 \pm 0.59$ & - \\
30 & $86.41 \pm 0.62$ & $87.03 \pm 0.29$ & $91.1 \pm 0.23$ & - \\
40 & $79.43 \pm 2.22$ & $85.65 \pm 1.20$ & $87.9 \pm 0.50$ & - \\
\hline 50 & $71.07 \pm 1.97$ & $79.15 \pm 0.58$ & $85.57 \pm 0.14$ & - \\
\hline
\end{tabular}




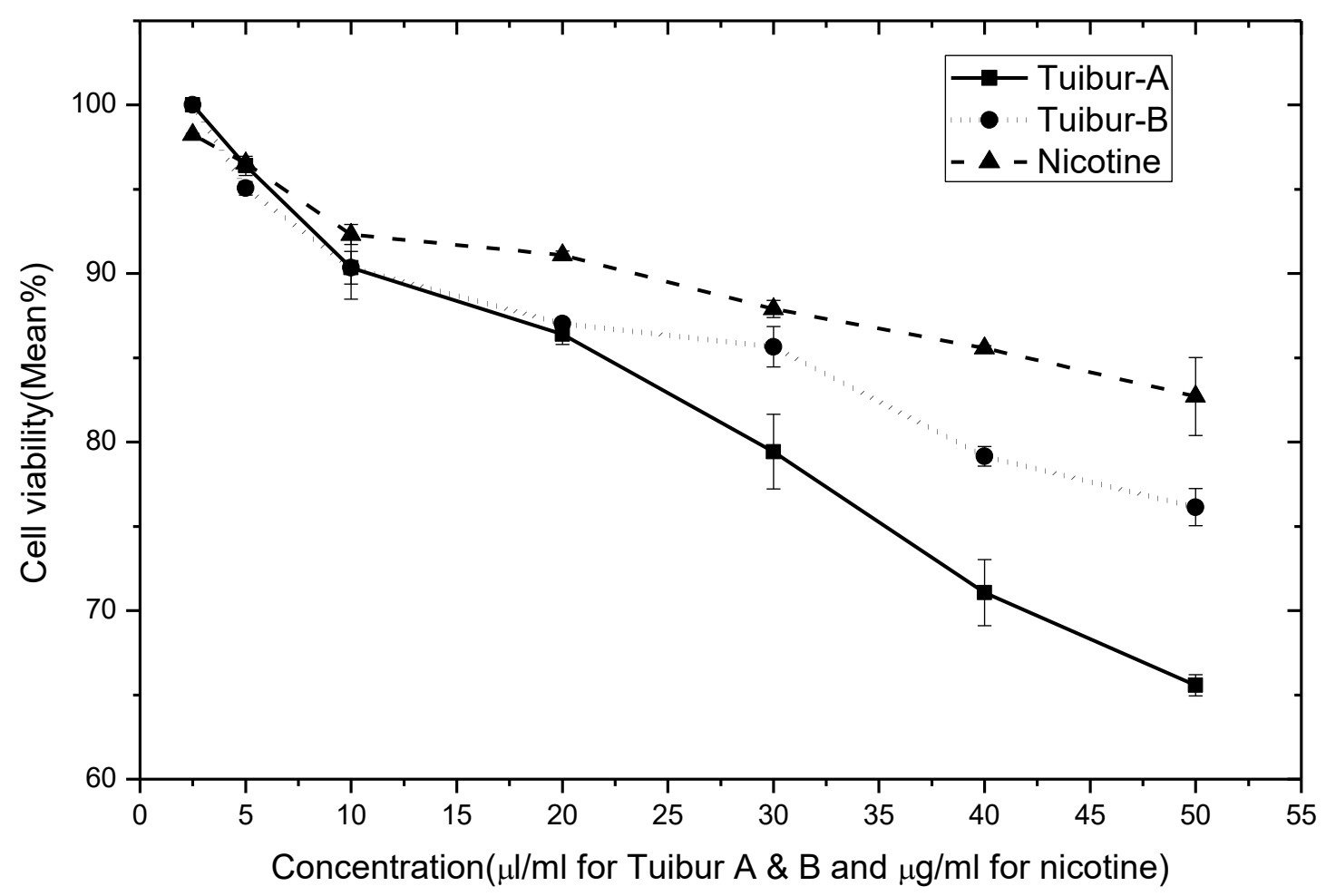

Figure 1 | Graph showing mean percentage of viable human peripheral blood lymphocytes treated with different concentration of tuibur-A, tuibur-B and nicotine.

tion coefficient was performed to determine relationship between different treatment concentrations and viability within a group. Student's $t$ test was employed to determine significant difference between the treatment groups.

Table 2 | Student's $t$-test between different treatment groups at $95 \%$ confidence interval.

\begin{tabular}{lcc}
$\begin{array}{l}\text { Student's t-test } \\
\text { between }\end{array}$ & $\begin{array}{c}\text { p-value } \\
\text { at 95\% } \\
\text { Cl }\end{array}$ & \multicolumn{1}{c}{ Inference } \\
\hline Tuibur-A \& Tuibur-B & 0.60 & No significant difference \\
\hline Tuibur-A \& Nicotine & 0.27 & No significant difference \\
\hline Tuibur-B \& Nicotine & 0.45 & No significant difference \\
\hline Control \& Tuibur-A & $\leq 0.00$ & Significant difference \\
\hline Control \& Tuibur-B & $\leq 0.00$ & Significant difference \\
\hline Control \& Nicotine & $\leq 0.00$ & Significant difference \\
\hline
\end{tabular}

\section{Results}

The $\mathrm{pH}$ of tuibur-A and tuibur-B were found to be 9.81 and 10.09 respectively. Table 1 and Figure 1 showed the mean percentage of viable cells for the different treatment groups. The negative control showed $100 \%$ viability while tuibur-A, tuibur-B and nicotine showed a concentration dependent viability. Lymphocytes treated with a maximum concentration of $50 \mu \mathrm{l} /$ mlof tuibur-A and tuibur-B showed $65.57 \%$ and $76.14 \%$ viability respectively while a minimum concentration of $2.5 \mu \mathrm{l} / \mathrm{ml}$ of both the two tuibur grades resulted in $100 \%$ viability in both the groups. A maximum concentration of $50 \mu \mathrm{g} / \mathrm{ml}$ and a minimum concentration of $2.5 \mu \mathrm{g} / \mathrm{ml}$ of nicotine showed $82.71 \%$ and $98.25 \%$ viability respectively. A strong negative correlation was observed between cell viability and concentration of tuibur-A (-0.994), tuibur-B (-0.969) and 
nicotine (-0.979). This means higher the concentration of the chemicals, lower the viability and vice versa.

Statistical analysis by t-test at $95 \% \mathrm{Cl}$ (Table 2) between mean percentage of viable cells for blank and tuibur-A, blank and tuibur-B, blank and nicotine showed a significant difference ( $p$ value $\leq 0.00$ ). However, comparison of tuibur-A and tuibur $-B$ ( $p$-value $=0.60)$, tuibur- $A$ and nicotine $(p$-value $=0.27)$, tuibur $-B$ and nicotine $(p$ value $=0.45$ ) showed that there is no significant difference in mean percentage of viable cells between these groups.

\section{Discussion}

Tobacco is known to contain enormous amount of different chemicals, many of which have been reported to have carcinogenic and cytotoxic properties. ${ }^{1,14}$ Most studies, if not all, reported the use of tobacco in any form only have negative impact on the physiological wellbeing of the users. There have been only a handful of literatures on the scientific investigation of tuibur. A preliminary report on the chemical composition of tuibur showed the presence of polyaromatic hydrocarbons and carbonyl compounds in the tar phase. ${ }^{11}$

An epidemiological study among the Mizos showed that tuibur users have a higher risk of developing gastric cancer and the combine use and frequency of smoking, betel, tuibur and sahdah were reported to have a significant influence on the risk of gastric cancer. ${ }^{10}$ Phukan et al. ${ }^{15}$ have also reported tuibur use as a risk factor for gastric cancer. Besides gastric cancer patients in Mizoram, tuibur consumers were found to have a variety of mtDNA D-loop region mutations and polymorphisms. ${ }^{16}$ Individuals with Arg/ Pro genotype,GSTM1 null genotype and GSTT1 non-null genotype were also suggested to have a higher risk of gastric cancer if they have habits of using tuibur and smoking tobacco. ${ }^{17,18}$

The damaging effect of tobacco may be attributed to its vast array of chemical compositions. Heavy metals like cadmium and lead present in tobacco have also been found to cause glomerular dysfunction. Many of these effects may be because of nicotine's ability to affect certain antioxidant enzymes like lipid peroxidase, superoxide dismutase, catalase, glutathione-stransferase, glutathione reductase, etc. ${ }^{3}$ Cytological studies have reported nicotine to inhibited cell proliferation and decreased protein synthesis in a dose dependent manner in cultured periodontal ligament fibroblast, ${ }^{19}$ while it was also reported to stimulate endothelial cell DNA synthesis and proliferation at concentrations lower than $<10^{-8} \mathrm{M}$. The cytotoxicity of nicotine was reported to be at a higher concentration, i.e. $>10^{-6} .20$

Onion bulbs treated with tuibur showed a reduced root growth, reduced mitotic index, formation of micronuclei, lagging chromosomes, and c-mitosis. ${ }^{21} \mathrm{~A}$ study on seven smokeless tobacco aqueous extracts showed a concentrationdependent effects on the growth and viability of oral bacteria cultured under anaerobic conditions. ${ }^{22}$ These effects may be a result of increase superoxide anion production, lipid peroxidation, DNA fragmentation and DNA ladders caused by the use of chewing tobaccos. ${ }^{23}$

Our result showed concentration dependent cell viability for the tuibur and nicotine treatment groups while the untreated negative control group showed $100 \%$ viability. We are uncertain as to what chemical(s) in the tobacco brew would cause the cells to die. But from the nicotine treatment group, we may be able to say, although carefully, that the nicotine might contributed significantly in this result. However, one study suggested other biologically active compounds like NNN, NNK, etc., other than nicotine present in tobacco leave extract to be the source of cytotoxicity. ${ }^{24}$

Another probable factor for the decrease in viability of the tuibur treatment groups would be the change in $\mathrm{pH}$ of the culture media. As we have shown in our result, the $\mathrm{pH}$ of both the two grades of tuibur are alkaline in nature, a slight rise in $\mathrm{pH}$ of the culture media was observed after the addition of both the tuibur (data not shown). This change in $\mathrm{pH}$ may be a factor that leads to decrease cell viability. In conclusion, our 
result showed that $24 \mathrm{~h}$ treatment of human lymphocytes with tuibur and nicotine may have an adverse effect on their survival and hence these chemicals might have cytotoxic properties. Therefore, the consumption of tuibur might have potential side effects on the health of the users.

\section{Acknowledgement}

The authors would like to thank Mr. B. Sanga Ralte for his valuable suggestions in the statistical analysis.

\section{References}

I. Arimilli S, Damratoski BE, Bombick B, Borgerding MF \& Prasad GL (20I2). Evaluation of cytotoxicity of different tobacco product preparations. Regul Toxicol Pharmacol, 64, 350-360.

2. Ding YS, Zhang L, Jain RB, Jain J, Wang RY, Ashley DL \& Watson CH (2008). Levels of tobacco-specific nitrosamines and polycyclic aromatic hydrocarbons in mainstream smoke from different tobacco varieties. Cancer Epidemiol Biomarkers Prev, 17, 12, 3366-337I.

3. Cooper RG (2006). Effect of tobacco smoking on renal function. Indian J Med Res, I24, 26I-268.

4. Stepanov I \& Hecht SS (2005). Tobacco-specific nitrosamines and their pyridine- $\mathrm{N}$-glucuronides in the urine of smokers and smokeless tobacco users. Cancer Epidemiol Biomarkers Prev, I4, 885-891.

5. Borgerding MF, Bodnar JA, Curtin GM \& Swauger JE (2012). The chemical composition of smokeless tobacco: A survey of products sold in the United States in 2006 and 2007. Regul Toxicol Pharmacol, 64, 367-387.

6. Musk AW \& De Klerk NH (2003). History of tobacco and health. Respirology, 8, 286-290.

7. Elmasry S, Asfour S, Vaccari JPR \& Travascio F (2015). Effects of tobacco smoking on the degeneration of the intervertebral disc: A finite element study. Plos One, -I22.

8. Jha P, Ranson MK, Nguyen SN \& Yach D (2002). Estimates of global and regional smoking prevalence in 1995 , by age and sex. Research and Practice, 92, 6, 1002-1006.

9. WHO Global Report on Trends in Prevalence of Tobacco Smoking 20I5. WHO Press, World Health Organi- zation, 20 Avenue Appia, I2II Geneva 27, Switzerland, pp. 4-359.

Io. Lalpawimawha, Lalruatfela B, Chenkual S, Ralte Z, Zomuana T, Ruatfela ST, Lalhruaitluanga W (2015). Association of tobacco use, betel consumption and gastric cancer in Mizoram. Sci Vis 15, 2, 59-67.

II. Lalmuanpuii R \& Muthukumaran RB (2016). Fourier transform-infrared spectroscopic characterization of the particulate phase of commercial tuibur. Sci Vis, 16, 2, 6873.

I2. Jagetia GC, Jayakrishnan A, Fernandes D\& Vidyasagar MS(200I). Evaluation of micronuclei frequency in the cultured peripheral blood lymphocytes of cancer patients before and after radiation treatment. Mutat Res, 491, 9-16.

13. Freshney, R. (1987). Culture of Animal Cells: A Manual of Basic Technique, Alan R. Liss, Inc., New York,p. II7.

14. Stepanov I, Hecht SS, Ramakrishnan S \& Gupta PC (2005). Tobacco-specific nitrosamines in smokeless tobacco products marketed in India. Int J Cancer, II6, I6I9.

15. Phukan RK, Zomawi E, Hazarika NC \&Mahanta J (2005). Tobacco use and stomach cancer in Mizoram, India; Cancer Epidemiol Biomarkers Prev, I4, 8, I892I896.

I6. Lalmuanpuii R, Ghatak S, Pautu JL, Lallawmzuali D, Muthukumaran RB \& Kumar NS (2015). Mutation profiling in mitochondrial D-loop associated with stomach cancer and tobacco consumers. JClin Med Genom, 3, I, I-5.

17. Malakar M, Devi KR, Phukan RP, Kaur T, Deka M, Puia L, Barua D, Mahanta J \& Narain K (2012). Genetic polymorphism of glutathione S-transferase $\mathrm{MI}_{\mathrm{I}}$ and $\mathrm{T}_{\mathrm{I}}$, tobacco habits and risk of stomach cancer in Mizoram, India. Asian Pacific J Cancer Prev, 13, 9, 4725-4732.

I8. Malakar M, Devi KR, Phukan RP, Kaur T, Deka M, Puia L, Sailo L, Lalhmangaihi T, Barua D, Rajguru SK, Mahanta J \& Narain K (2014). p53 codon 72 polymorphism interactions with dietary and tobacco related habits and risk of stomach cancer in Mizoram, India. Asian Pacific J Cancer Prev, 15, 2, 717-723.

19. Chang YC, Huang FM, Tai KW, Yang LC \& Chou MY (2002). Mechanism of cytotoxicity of nicotine in human periodontal ligament fibroblast cultures in vitro. J Perio- 
dont Res, 37, 279-285.

20. Villablanca AC (1998). Nicotine stimulates DNA synthesis and proliferation in vascular endothelial cells in vitro.J Appl Physiol, 84, 6, 2089-2098.

2I. Ra B (2012). Chemistry and toxicology of smokeless tobacco. Indian J Cancer, 49, 4, 364-372.

22. Liu M, Jin J, Pan H, Feng J, Cerniglia CE, Yang M \& Chen $\mathrm{H}$ (2016). Effect of smokeless tobacco products on human oral bacterial growth and viability. Anaerobe, 42, I52-16I.
23. Bagchi M, Balmoori J, Bagchi D, Stohs SJ, Chakrabarti J $\&$ Das DK (2002). Role of reactive oxygen species in the development of cytotoxicity with various forms of chewing tobacco and pan masala. Toxicology, 179, 247255.

24. Moghbel N, Ryu B, Cabot PJ \& Steadman KJ (2016). In vitro cytotoxicity of Nicotiana gossei leaves, used in the Australian aboriginal smokeless tobacco known as pituri or mingkulpa. Toxicol Lett, 254, 45-5I. 